\title{
A vivência dos trabalhadores de um CAPS diante da nova organização do trabalho em equipe ${ }^{1}$
}

\author{
The experience of the workers of a CAPS facing the new team work organization
}

\author{
La vivencia de los trabajadores de un CAPS frente a la nueva organización \\ del trabajo en equipo
}

\author{
Carmen Lúcia Alvez Filizola', Débora Brechesi Milioni", Sofia Cristina Iost Pavarini"l
}

\section{RESUMO}

O CAPS - Centro de Atenção Psicossocial, serviço substitutivo ao manicômio, propõe um novo arranjo organizacional. O objetivo desta pesquisa foi analisar a vivência dos trabalhadores do CAPS de São Carlos - SP diante da nova organização do trabalho em equipe em saúde mental. Trata-se de estudo qualitativo realizado através de observação de campo e entrevistas. A observação revelou que o trabalho vem ao encontro da proposta de trabalho interdisciplinar na saúde mental. Da análise das entrevistas com 17 trabalhadores apreendemos três grandes categorias: 1 . Considerando a experiência de trabalho em equipe como um processo, identificando pontos positivos, conflitos e dificuldades; 2 . Reconhecendo a diferença do trabalho no CAPS em relação aos trabalhos anteriores; 3 . Vivenciando dificuldades no início, adaptando-se e aprendendo a gostar. Ressaltamos a importância da nova organização do trabalho que possibilita maior vínculo com os usuários gerando satisfação no trabalho, autonomia e aprendizagem. Há necessidade de mudanças nas condições de trabalho com implementação efetiva de políticas públicas voltadas para a desprecarização do trabalho em saúde.

Palavras chave: Serviços de saúde mental; Equipe de assistência ao paciente; Desinstitucionalização.

\footnotetext{
ABSTRACT

The CAPS - Psychosocial Care Center, substitute service to the insane asylum, considers a new organizational arrangement. The objective of this research was to analyze the experience of the workers of the CAPS of São Carlos - SP facing the new team work organization in mental health. It is a qualitative research carried out through field observation and interviews. The observation disclosed that the work comes to meet the interdisciplinar work proposal in mental health. From the analysis of
}

the interviews with 17 workers we apprehended three great categories: 1 . Considering the experience of team work as a process, identifying positive points, conflicts and difficulties; 2. Recognizing the difference of the work in the CAPS in relation to previous works; 3. Living the difficulties at the beginning, adapting and learning how to like. We stand out the importance of the new organization of the work that makes possible greater bond with the users generating satisfaction in the work, autonomy and learning. There is the necessity of changes in the working conditions with the implementation of effective public policies directed to the improvement of the work in health.

Key words: Mental health services; Patient care team; Deinstitutionalization.

\section{RESUMEN}

EI CAPS - Centro de Atención Psicosocial, servicio sustitutivo al manicomio, propone un nuevo arreglo organizacional. El objetivo de este trabajo investigación, fue el de analizar la vivencia de los trabajadores del CAPS de San Carlos - SP frente a la nueva organización del trabajo en equipo sobre salud mental. Se trata de un estudio cualitativo realizado a través de

\footnotetext{
${ }^{1}$ Pesquisa financiada pelo CNPq (PIBIC/CNPq-UFSCar 20062007)

Enfermeira. Doutora em Enfermagem pela USP-RP. Professora Associada do Departamento de Enfermagem da Universidade Federal de São Carlos. Líder do Grupo de Pesquisa Saúde Mental no contexto da Reforma Psiquiátrica do CNPq e Membro do Grupo de Pesquisa Saúde e Família. E-mail: filizola@power.ufscar.br

"Aluna do Curso de Graduação em Enfermagem da UFSCar. Bolsista PIBIC-CNPq-UFSCar. 2006-2007. Membro do Grupo de Pesquisa Saúde Mental no contexto da Reforma Psiquiátrica do CNPq. E-mail: deboramilioni@hotmail.com III Enfermeira. Doutora em Educação pela UNICAMP. Professora Associada do Departamento de Enfermagem da Universidade Federal de São Carlos. Líder do Grupo de Pesquisa Saúde e Envelhecimento do CNPq e Membro do Grupo de Pesquisa Saúde e Família. E-mail: sofia@ufscar.br
} 
Filizola CLA, Milioni DB, Pavarini SCI. A vivência dos trabalhadores de um CAPS diante da nova organização do trabalho em equipe. Revista Eletrônica de Enfermagem [Internet]. 2008;10(2):491-503. Available from: http://www.fen.ufg. br/revista/v10/n2/v10n2a20.htm

observación de campo y entrevistas. La observación reveló que el trabajo viene al encuentro de la propuesta de trabajo interdisciplinar en salud mental. Del análisis de las entrevistas con 17 trabajadores consideramos tres grandes categorías: 1 . Considerando la experiencia de trabajo en equipo como un proceso, identificando puntos positivos, conflictos y dificultades; 2. Reconociendo la diferencia del trabajo en el CAPS con relación a los trabajos anteriores; 3. Evidenciando dificultades al inicio, adaptándose y aprendiendo a gustar. Resaltamos la

\section{NTRODUÇÃO}

A Reforma Psiquiátrica constitui-se em um processo social complexo de dimensão teóricoconceitual, jurídico-política, técnico-assitencial e sociocultural ${ }^{(1)}$. Os novos dispositivos de saúde mental pautam-se na multidimensionalidade e complexidade da atenção às pessoas com transtornos mentais graves, na reabilitação psicossocial, na construção de autonomia, na construção da cidadania, na inclusão social das pessoas em sofrimentos psíquicos, valorizando as atividades da vida cotidiana e atuando no território de forma a fomentar redes de apoio(1).

No Brasil, o processo da Reforma Psiquiátrica prevê a criação de uma rede de serviços substitutivos ao manicômio sendo os Centros de Atenção Psicossocial (CAPS) o eixo dessa rede ${ }^{(2)}$. Os CAPS se contrapõem ao modelo da hospitalização e têm como população alvo os pacientes com transtorno mental e de comportamento, principalmente, psicóticos e neuróticos graves. Eles são serviços abertos e comunitários pertencentes ao Sistema Único de Saúde (SUS) tendo como objetivo a reabilitação psicossocial de seus pacientes ${ }^{(2)}$.

Uma das diretivas apontada para a construção dos novos serviços da rede de atenção em saúde mental é o trabalho em equipe multiprofissional organizado de forma interdisciplinar. $O$ conceito de interdisciplinaridade surgiu no século $X X$ e, somente a partir da década de 60 passa a ser enfatizado como necessidade de transcender e atravessar o conhecimento fragmentado, mesmo tendo sempre existido, em menor ou maior escala, uma certa aspiração à unidade do saber $^{(3)}$. A organização fragmentada do trabalho importancia de la nueva organización de trabajo que posibilita un mayor vínculo con los usuarios generando satisfacción en el trabajo, autonomía y aprendizaje. Existe la necesidad de cambios en las condiciones de trabajo con implementación efectiva de políticas públicas destinadas al mejoramiento del trabajo en el área de la salud.

Palabras clave: Servicios de salud mental; Grupo de atención al paciente; Desinstitucionalización.

em equipe em saúde mental já era combatida por Franco Basaglia para quem a rigidez da especialização nos serviços de saúde mental tinha como efeito mais nocivo a fragmentação do processo terapêutico, segundo uma lógica estranha às necessidades dos enfermos ${ }^{(6)}$. Essa nova diretriz apresentada para o trabalho em saúde mental nos novos serviços de saúde mental teve na experiência ocorrida no município de Santos (SP) uma referência na área. Tal experiência fundamentou-se no princípio básico de não seguir as "supostas especificidades ou saberes" das várias categorias que compõem a equipe, resultado das críticas emergidas na época sobre o trabalho em equipe na saúde mental ${ }^{(4)}$.

Frente a tais críticas os novos serviços de saúde mental têm diante de si as novas proposições para o trabalho em equipe, ou seja, os conceitos de Campo e Núcleo de saberes e práticas com definição inequívoca de responsabilidade ${ }^{(5,6)}$. Núcleo conforma uma aglutinação de conhecimentos e de um determinado padrão concreto de um compromisso com a produção de valores de uso, demarcando a identidade de uma determinada área de saber e de prática profissional. Campo é o espaço sem limites precisos em que cada disciplina ou profissão busca apoio em outra a fim de cumprir suas tarefas teóricas e práticas. Esses dois conceitos são mutantes e interinfluenciados, sem a possibilidade de detecção dos limites precisos entre um e outro ${ }^{(5,6)}$.

Em relação a definição precisa de responsabilidade, esta implica em responsabilizar-se pelo seguimento de cada 
Filizola CLA, Milioni DB, Pavarini SCI. A vivência dos trabalhadores de um CAPS diante da nova organização do trabalho em equipe. Revista Eletrônica de Enfermagem [Internet]. 2008;10(2):491-503. Available from: http://www.fen.ufg. br/revista/v10/n2/v10n2a20.htm

caso $^{(6)}$. Assim surge, nessa nova organização do trabalho, o profissional ou técnico de referência ${ }^{(7)}$.

Sobre este "novo profissional", o técnico de referência, a análise do trabalho em um Núcleo de Atenção Psicossocial (NAPS) do município de Santos demonstrou que, para os trabalhadores daquele serviço, o trabalho no NAPS transcendia os papéis profissionais, as suas especificidades e que todos deveriam ter um trabalho comum, sendo parte do seu trabalho a responsabilidade em ser referência de um certo número de usuários. Ao analisar o que significava ser técnico de referência, para os trabalhadores daquele serviço, encontrou-se que ele significava todo um trabalho de aproximação, de criação do vínculo terapêutico, de acolhimento, de elaborar junto com o usuário um Projeto Terapêutico Individual e do trabalho com a família. Significava, ainda, aumentar o poder contratual do usuário que é considerado como modelo de referência da reabilitação psicossocial ${ }^{(7)}$.

Entretanto, pesquisas ${ }^{(8-9)}$ que analisam o trabalho em equipes de saúde mental nos novos dispositivos de atenção em saúde mental vêm apontando tensões existentes na delimitação do saber e de campos específicos do conhecimento. Outras analisam a especificidade do trabalho do enfermeiro e da enfermagem apontando que este implica em novos posicionamentos e novos saberes ${ }^{(10-12)}$.

Em nosso contexto, o CAPS de São Carlos (SP), inaugurado em 2002, busca uma atenção integral, entendendo saúde como produção de vida, de qualidade de vida e da construção da cidadania das pessoas que passam pela experiência de sofrimento psíquico, portanto, está pautado na reabilitação psicossocial. É um serviço aberto que oferece cinco settings de atendimento: individual, em grupo, oficina terapêutica, convivência e visitas domiciliares. Em relação à organização do trabalho neste serviço e, seguindo as diretrizes para os novos serviços de atenção em saúde mental, o trabalho também é realizado por equipe multiprofissional que busca construir uma prática interdisciplinar, portanto, não centrada nas especificidades ou saberes das várias categorias que compõem a equipe.
Porém, na vivência do cuidado neste serviço ouvimos, por vezes, questionamentos sobre o desenvolvimento de algumas atividades que os trabalhadores pensam não ser da competência de sua profissão, como exemplo, "Mas eu sou (categoria profissional) e não acho que deveria fazer isso. O meu trabalho era...", "Eu não acho que (categoria profissional) deveria fazer oficina terapêutica, isso é trabalho do ...". Entretanto, estes não parecem ser os questionamentos de todos. Diante do exposto realizamos esta pesquisa com o objetivo de analisar a vivência dos trabalhadores do CAPS de São Carlos diante da nova organização do trabalho em equipe em saúde mental. Também foram nossos objetivos caracterizar os trabalhadores da equipe e identificar, com maior profundidade a divisão das atividades e de responsabilidades entre os trabalhadores neste serviço.

\section{METODOLOGI A}

O presente estudo insere-se nos pressupostos do método qualitativo de investigação. $O$ método qualitativo é o que se aplica ao estudo da história, das relações, das representações, das crenças, das percepções e das opiniões, produtos das interpretações que os humanos fazem a respeito de como vivem, constroem seus artefatos e a si mesmos, sentem e pensam ${ }^{(13)}$.

\section{Sujeitos da pesquisa}

Foram considerados sujeitos deste estudo os trabalhadores do CAPS de São Carlos (SP), que concordaram em participar. De um total de 20 trabalhadores, 17 participaram da pesquisa: um médico, uma enfermeira, duas terapeutas ocupacionais, um psicólogo, uma assistente social, quatro auxiliares de enfermagem, um auxiliar administrativo, três auxiliares de serviços gerais, um vigia, um porteiro e uma professora. Duas trabalhadoras (uma psicóloga e uma auxiliar administrativa) que não concordaram em ser entrevistadas alegaram não querer participar justificando falta de tempo e uma professora não foi possível contato, pois se encontrava em férias durante o período da coleta de dados. 
Filizola CLA, Milioni DB, Pavarini SCI. A vivência dos trabalhadores de um CAPS diante da nova organização do trabalho em equipe. Revista Eletrônica de Enfermagem [Internet]. 2008;10(2):491-503. Available from: http://www. fen.ufg. br/revista/v10/n2/v10n2a20.htm

Todos os princípios éticos da pesquisa envolvendo seres humanos foram considerados, sendo a coleta de dados realizada após a aprovação pelo Comitê de Ética em pesquisa da Universidade Federal de São Carlos, segundo Parecer $N^{\circ}$ 292/2006. Os trabalhadores integrantes da pesquisa que concordaram em participar assinaram o consentimento livre e esclarecido obedecendo aos padrões estabelecidos pela Resolução 196/96.

\section{Coleta, registro e análise dos dados}

A coleta de dados ocorreu em duas etapas. Na primeira, realizamos observação de campo, com objetivo de conhecer a dinâmica do funcionamento do serviço, apreender as várias atividades/momentos do trabalho no CAPS, a divisão do trabalho e de responsabilidades entre os trabalhadores. Teve a duração de dez dias sendo os dados anotados em um diário de campo subsidiando a apresentação da análise das atividades dos vários elementos da equipe neste serviço.

$\mathrm{Na}$ segunda etapa realizamos entrevistas pautadas na definição de entrevista ${ }^{(14)}$ como sendo um processo de interação entre pesquisador-pesquisado tendo iniciado com a seguinte questão norteadora: "Como tem sido para você a experiência no trabalho em equipe aqui no CAPS?". Após esta, outras perguntas foram sendo formuladas com intuito de aprofundar o tema em estudo.

As entrevistas foram realizadas conforme a disponibilidade dos trabalhadores, no próprio CAPS, em horário estabelecido pelos próprios entrevistados. No final destas, foi aplicado a todos os entrevistados um roteiro previamente elaborado para caracterizar os trabalhadores entrevistados quanto a alguns dados de identificação (idade, sexo, estado civil), experiência profissional e qualificação.

A coleta de dados ocorreu no período de dezembro de 2006 a março de 2007. Todas as entrevistas foram gravadas, transcritas e analisadas posteriormente através da análise de conteúdo, modalidade temática(15). Para preservar a identidade dos trabalhadores elas foram identificadas no texto apenas através de um número.

$\mathrm{Da}$ análise minuciosa dos dados
apreendemos três Grandes Categorias

(representadas em letra maiúscula e negrito) sendo, cada uma delas, composta por categorias (letra minúscula e em negrito) e subcategorias (letras minúsculas e sublinhadas).

Assim, apresentamos, primeiramente, a caracterização dos trabalhadores, a seguir a análise dos dados obtidos mediante a observação de campo e, finalmente, a vivência dos trabalhadores no trabalho em equipe.

\section{RESULTADOS E DISCUSSÃO}

\section{Caracterização dos trabalhadores}

A caracterização dos trabalhadores revelou que a maioria é composta por mulheres (76\%) refletindo pesquisas na área da saúde demonstrando haver uma tendência em associar o trabalho feminino no cuidado de outras pessoas, trabalho este, que envolve qualidades de destreza, paciência, interesse em ser útil e dedicação, características tais pautadas como "femininas" na nossa sociedade e em outras ${ }^{(16)}$.

Quanto à faixa etária e ao estado civil, há predominância dos trabalhadores entre 41 e 50 anos (35\%) seguida dos que se encontram entre os 21 a 30 anos (29\%) sendo a maioria casados $(65 \%)$. Em relação à experiência profissional e capacitação, como era de se esperar, verificamos que a maioria dos trabalhadores de nível superior tem mais experiência e maior preparo que os de nível técnico e médio, pois os primeiros revelaram possuir maior tempo de atividade profissional e experiência em saúde mental, assim como outros cursos na área.

Ao analisarmos os dados relativos aos vínculos empregatícios verificamos a presença de contratação temporária (duas auxiliares de enfermagem) e substitutiva (do médico) assim como contratação via cooperativa (uma auxiliar de limpeza) e terceirização (do porteiro e do vigia). Pesquisa sobre a força de trabalho em serviço substitutivo também aponta diversas formas de contratação em todas as categorias profissionais, havendo flexibilização das relações trabalhistas, consideradas como formas irregulares de inserção no serviço público ${ }^{(16)}$. 
Filizola CLA, Milioni DB, Pavarini SCI. A vivência dos trabalhadores de um CAPS diante da nova organização do trabalho em equipe. Revista Eletrônica de Enfermagem [Internet]. 2008;10(2):491-503. Available from: http://www. fen.ufg. br/revista/v10/n2/v10n2a20.htm

Frente a este fato, concordamos com análise dos autores ${ }^{(16)}$ quando assinalam que tais formas de contratação precarizam o trabalho sendo fonte de exclusão progressiva dos trabalhadores que não se ajustam às imposições desta nova ordem. Ainda em concordância com estes autores salientamos que a flexibilização das formas de trabalho gera salários mais baixos sendo um fenômeno resultante do mundo globalizado que vem afetando, também, o setor de serviços, como o da saúde ${ }^{(16)}$.

\section{A nova organização do trabalho em equipe no CAPS - as atividades e a divisão do trabalho e de responsabilidades entre os trabalhadores.}

A observação de campo proporcionou constatar a complexidade do trabalho no CAPS. Trata-se de um CAPS II, portanto, com horário de funcionamento das 8 às 18 horas, de segunda à sexta-feira. $O$ serviço oferece atendimento aos usuários com quadro severo de sofrimento psíquico em regime de tratamento intensivo (o usuário passa o dia todo), semi-intensivo (ele permanece um período do dia) e não-intensivo (ele vai ao serviço para os atendimentos agendados).

Ao observar o funcionamento do serviço foi possível identificar que o trabalho ali realizado compreende várias atividades oferecidas aos usuários e famílias às quais podemos identificá-las como terapêuticas e de suporte ao trabalho (embora reconhecemos que tal diferenciação não seja dicotômica), educativas e de inclusão social pelo trabalho.Tais atividades são apresentadas a seguir com seus respectivos responsáveis, demonstrando na prática deste serviço como se dá a organização em campo e núcleo de competências: recepção (auxiliares administrativas), acolhimento/triagem (trabalhadores de nível superior), acompanhamento terapêutico individual (técnico de referência), atendimentos psicoterápicos individuais e grupais (psicólogos e terapeuta ocupacional), atendimento de orientação individual (assistente social) e grupal (enfermeira e auxiliar de enfermagem), grupo de família (assistente social), várias oficinas terapêuticas (trabalhadores de nível superior, auxiliares de enfermagem e o vigia que oferece uma oficina de música), projeto de geração de trabalho e renda na perspectiva da Economia Solidária (terapeuta ocupacional/Coordenadora do CAPS, uma psicóloga, auxiliares de enfermagem), assembléia de usuários (coordenada pela coordenadora do CAPS, mas com participação da maioria dos trabalhadores), atividades esportivas, festas e passeios (coordenadas pelas auxiliares de enfermagem com participação da maioria dos trabalhadores), reunião de equipe (todos participam, exceto o atual médico), ambiência (todos realizam, exceto o atual médico), visita domiciliária (técnicos de referência), consulta médica (médico), atividades de cuidado - banho, alimentação e administração da medicação (trabalhadores da enfermagem). As atividades educacionais se dão através do MOVA (Movimento da Alfabetização de Adultos) e EJA (Ensino de Jovens e Adultos), sendo as duas professoras pertencentes à equipe as responsáveis. Cabe salientar que as atividades de educação e de inclusão social pelo trabalho (projeto de geração de trabalho e renda na perspectiva da Economia Solidária) são realizadas em parceria com a Secretária Municipal de Educação e com a Universidade Federal de São Carlos (Departamento de Enfermagem e INCOOP - Incubadora de Cooperativas Populares), respectivamente. Diante dessas parcerias ressaltamos a concretização, na prática deste serviço, da diretriz da intersetorialidade presente no paradigma do modelo de atenção psicossocial.

Destaca-se, em relação à divisão/organização do trabalho neste CAPS, a presença do profissional técnico de referência o que atende à recomendação do trabalho interdisciplinar com definição precisa de responsabilidade. Neste serviço o técnico de referência é o responsável pelo acompanhamento terapêutico individual sendo, portanto, o profissional que formula o projeto terapêutico individual (PTI) juntamente com o usuário, identificando com ele as atividades e a freqüência de sua participação o que são definidos conforme sua necessidade e interesse. Os trabalhadores que assumem o papel de 
Filizola CLA, Milioni DB, Pavarini SCI. A vivência dos trabalhadores de um CAPS diante da nova organização do trabalho em equipe. Revista Eletrônica de Enfermagem [Internet]. 2008;10(2):491-503. Available from: http://www.fen.ufg.br/revista/v10/n2/v10n2a20.htm

referência são:a enfermeira, uma terapeuta ocupacional (a outra está na coordenação do serviço), os psicólogos, assistente social e as três auxiliares de enfermagem.

Observamos que esses técnicos procuram acompanhar seus usuários de referência, realizando atendimento individual portanto, a escuta do usuário, o vínculo, a coleta da história de vida e a constante busca em encontrar soluções e dar encaminhamento para os problemas apresentados pelos usuários no seu processo de reabilitação psicossocial. Também se relacionam e observam suas referências durante sua permanência no serviço, quando também se interagem com todos os usuários o que é denominado de ambiência. Faz parte do trabalho da referência o cuidado à família, o monitoramento do PTI avaliando se as metas traçadas estão sendo alcançadas. Também é a referência quem realiza as visitas domiciliárias aproximando o serviço do contexto de vida do usuário, acompanha a sua freqüência, adaptação no CAPS e à medicação sendo o elo entre o usuário e a equipe. Verificamos ainda que cada técnico tem em torno de 25 referências e que, por vezes, os trabalhadores trocam entre si as referências conforme o grau de afinidade/vínculo

e/ou facilidades/dificuldades ao lidar com determinado usuário.

Um outro momento/atividade/espaço do trabalho neste CAPS, também importante em ser ressaltado tendo em vista atender as novas diretrizes do trabalho em equipe nos equipamentos de saúde mental se refere às reuniões de equipe. Neste serviço ela se constitui no momento em que toda a equipe se reúne para refletir sobre o trabalho, discutir dúvidas, trocar idéias a respeito dos casos, trocar saberes e experiências de cada trabalhador envolvido. É também um espaço para discutir a organização do trabalho, a divisão das tarefas entre os trabalhadores para sua melhor organização. Os trabalhadores presentes na reunião participam da discussão dos casos de cada usuário e do encaminhamento a ser dado a cada um deles em cada situação de forma a tomar conhecimento das condutas a serem seguidas.
Ela acontece uma vez por semana e todos os trabalhadores participam com exceção do atual médico, do vigia e das auxiliares administrativas. Quanto aos últimos, eles não participam pois não podem deixar de exercer suas funções na hora da reunião, uma vez que o vigia é responsável pela segurança do serviço e, as auxiliares que, embora sejam duas, uma delas apenas trabalha no período da tarde. Entretanto, este limite não significa que, em outros momentos/espaços, eles não se apropriem das discussões e decisões tomadas na reunião. Em relação à participação do médico, como identificado na caracterização dos trabalhadores este apresenta contrato temporário como substituto, com menor carga horária de trabalho que a do médico efetivo, ou seja, insuficiente para a realização das atividades que são preconizadas para esse novo modelo de cuidado.

Frente a esta realidade consideramos que a divisão do trabalho neste CAPS vem ao encontro da proposta de trabalho interdisciplinar no campo da saúde mental uma vez que os trabalhadores desenvolvem atividades consideradas como sendo do CAMPO e do NúCLEO de competência de suas profissões com definição precisa de responsabilidade $^{6}$. Tal consideração se justifica tendo em vista que o único profissional que não realiza as atividades de Campo encontra-se em situação peculiar, ou seja, de contratação temporária de trabalho. Por outro lado, não podemos deixar de reafirmar a questão da precarização do trabalho na saúde também presente neste serviço.

\section{A vivência dos trabalhadores no trabalho em equipe no CAPS}

Através da análise das entrevistas com os trabalhadores apreendemos três Grandes Categorias que expressam a vivência dos trabalhadores no trabalho em equipe no CAPS e buscam relatar como os trabalhadores consideram essa experiência. São elas: "Considerando a experiência de trabalho em equipe como um processo, identificando pontos positivos, conflitos e dificuldades", "Reconhecendo as diferenças do trabalho no CAPS em relação aos trabalhos anteriores" e 
Filizola CLA, Milioni DB, Pavarini SCI. A vivência dos trabalhadores de um CAPS diante da nova organização do trabalho em equipe. Revista Eletrônica de Enfermagem [Internet]. 2008;10(2):491-503. Available from: http://www. fen.ufg. br/revista/v10/n2/v10n2a20.htm

"Vivenciando dificuldades no início, adaptandose e aprendendo a gostar".

\section{CONSI DERANDO A EXPERIÊNCIA DE TRABALHO EM EQUIPE COMO UM PROCESSO, IDENTI FICANDO PONTOS POSI TI VOS, CONFLITOS E DIFI CULDADES}

Os trabalhadores relatam que a experiência de trabalho em equipe é um processo, em que se encontram pontos positivos, mas também referem existir dificuldades, que fazem parte deste novo contexto de trabalho.

\section{Reconhecendo o trabalho como um processo de construção}

Os trabalhadores relatam que o trabalho em equipe no serviço vem se construindo desde o início de sua implantação, passando por vários momentos sendo, portanto, um processo. Consideram o momento atual como algo muito especial.

... foi um processo mesmo de construção das pessoas poderem estar se colocando, se questionando sem sentir e levar pro lado pessoal. Hoje a gente já ta num nível bastante evoluído [...] teve momentos muito difíceis nessa construção..." (E13)

\section{I dentificando pontos positivos}

Para a maioria dos entrevistados a experiência tem sido muito boa porque existem vários elementos positivos das relações humanas e da organização do trabalho.

Presença de elementos positivos das relações interpessoais

Os trabalhadores afirmam existir entre eles colaboração, divisão precisa de responsabilidade, busca de entendimento diante das diferentes visões, respeito pelo outro, amizade, capacidade de ouvir o outro, companheirismo, união e tomada de decisão conjunta.

... é um companheirismo. Todo mundo trabalha junto... (E2)

... a gente trabalha num grupo de amigos [...] são tudo bons companheiros pra trabalhar. (E9)
... no CAPS os profissionais, eles têm um certo respeito por cada um, ou pelo outro dentro, ouve... (E5)

... quando você trabalha com uma equipe, você, às vezes, pensa de uma maneira, vai agir de uma maneira, um outro profissional vem, você discute, chega em você e abre outros caminhos... (E5)

O trabalho em equipe em saúde apresenta-se como "uma rede de relações entre pessoas, relações de poderes, saberes, afetos, e desejos". Trabalhar em equipe implica em se relacionar, no sentido de desenvolver uma tarefa em conjunto, tendo esta que ser maior do que a soma das parcelas de trabalho de cada um da equipe ${ }^{(17)}$.

\section{Possibilitando o aprendizado}

A maioria dos entrevistados considera a experiência em equipe como uma experiência nova e muito boa, em que tem aprendido bastante devido a troca de experiência e conhecimento que cada profissional traz para compartilhar. O aprendizado também acontece pelo contato com estagiários (o serviço é local de ensino de vários cursos da área da saúde) que levam à necessidade de atualização constante e preocupação com a formação dos novos profissionais para o novo modelo.

Tem sido ótima (a experiência), dá pra aprender muita coisa. Como dizem aprendendo e vivendo. Então, estou aprendendo bastante. (E8)

Um estudo(18) com trabalhadores de um serviço substitutivo também aponta que a vivência cotidiana do trabalho no CAPS é responsável pela aquisição e acréscimos no saber.

Reconhecendo a importância de se trabalhar no novo modelo, na nova organização do trabalho em equipe e da consideração de todos os trabalhadores como membros da equipe

Os trabalhadores reconhecem que, a nova proposta de organização do trabalho em equipe no CAPS e a consideração de que todos os elementos do CAPS, independente de cargo/função ou formação, possibilita que todos se sintam membros da equipe, sendo, portanto, respeitados, reconhecidos, valorizados e 
Filizola CLA, Milioni DB, Pavarini SCI. A vivência dos trabalhadores de um CAPS diante da nova organização do trabalho em equipe. Revista Eletrônica de Enfermagem [Internet]. 2008;10(2):491-503. Available from: http://www.fen.ufg.br/revista/v10/n2/v10n2a20.htm

participantes do processo de reabilitação psicossocial.

... aqui você percebe que todo mundo, todo mundo mesmo, desde a faxineira, porteiro, vigilante até o médico psiquiatra e a diretora do CAPS, todo mundo trabalha junto, é um time mesmo. Não tem distinção, não tem preconceito, não tem diferença, todo mundo é a equipe... (E2)

Tendo prazer/satisfação no trabalho devido a possibilidade de manter maior vínculo com os usuários, ver a sua melhora e supervisionar estagiários

Os trabalhadores demonstraram gratificação em trabalhar no CAPS, não somente pela nova organização de trabalho e por trabalhar em um novo modelo, mas pela possibilidade de manter um vínculo muito próximo com os usuários e em poder ver a sua melhora, portanto, o resultado do seu trabalho. A oportunidade de ter estagiários no CAPS, e poder supervisioná-los mostrou ser, também, uma fonte de gratificação no trabalho para uma trabalhadora.

... é muito bom (estar mais próximos dos usuários), têm alguns que tem um vínculo que é grande, que é bom que acabaram confiando em mim, me contam problemas... (E2)

... é gratificante, assim, você vê que o paciente está bem. E eles se apegam muito com a

gente. (E1)

Uma coisa que eu faço que é bastante gratificante é que eu sou supervisora de aluno... (E13)

\section{Reconhecendo, também, que há conflitos, dificuldades e necessidade de melhores condições de trabalho}

Embora os trabalhadores tenham demonstrado satisfação com o trabalho em equipe, sua nova organização e o novo modelo de cuidado, trazendo os pontos positivos, também referem algumas dificuldades.

\section{Implementar o novo modelo de cuidado}

Construir o novo modelo de cuidado, fazer os profissionais entenderem esse novo olhar, a mudança de modelo tem sido uma dificuldade para uma das entrevistadas.
Olha, uma dificuldade que eu sinto [...] é a própria implementação dessa nova concepção [...] Foi uma desconstrução. Desconstruir um modelo é muito mais difícil do que você construir um modelo com quem entrava novo... (E13)

Despertar nas pessoas a necessidade de conhecer outros mundos não é algo fácil, e mudar os padrões da relação profissionais da saúde/clientela é o ponto chave de qualquer projeto que pretende mudar o modo de atenção, mas que se torna difícil devido à alienação dos trabalhadores de saúde e com a ineficácia da clínica e da saúde pública ${ }^{(6)}$.

\section{Relações de trabalho e falta de união}

Alguns dos entrevistados vêem problemas de relacionamento na equipe e a falta de união entre os trabalhadores para a realização das atividades como também estando presentes na equipe.

... (precisa de) um pouco mais de união, todo mundo trabalhar igual... (E7)

O trabalho em equipe tem sido considerado como uma rede de relações que requer permanente atenção e análise por parte dos próprios trabalhadores, porque é um trabalho que vai se constituindo no dia-a-dia, sendo passível de dificuldades, paralisações ${ }^{(17)}$.

\section{Lidar com os usuários}

O lidar com os usuários traz algumas dificuldades para alguns trabalhadores. Estas passam tanto pelo saber o que falar, como com o despertar o interesse/atenção deles, o lidar com os comportamentos e instabilidade, o como agir no momento da crise e com o porte de arma de usuários, o que requer muito cuidado e "jogo de cintura".

Ah, eu acho que a dificuldade é de lidar com eles mesmos (os usuários) [...] a gente tem que saber o que falar, porque, de repente, pode acarretar alguma coisa... (E1)

\section{Diferentes visões e/ou pontos de vista}

Outra dificuldade apresentada pelos entrevistados refere-se às diferenças entre os mesmos, as quais incluem experiências, abordagens e/ou pontos de vista contrastantes entre os trabalhadores e, quando não há um 
Filizola CLA, Milioni DB, Pavarini SCI. A vivência dos trabalhadores de um CAPS diante da nova organização do trabalho em equipe. Revista Eletrônica de Enfermagem [Internet]. 2008;10(2):491-503. Available from: http://www.fen.ufg. br/revista/v10/n2/v10n2a20.htm

acordo comum mediante tais diferenças. Sendo esta uma questão que necessita maior avanço no CAPS, embora uma trabalhadora reconhece o conflito como algo inerente ao trabalho em equipe.

... a diferença entre as pessoas, diferença de abordagem, diferença de linha de trabalho... (E6)

... tem algumas divergências de pensamento, de postura que é muito saudável. Eu acho assim, não existe equipe sem conflito, que senão ela não é uma equipe, é uma mentira. Por que? Para que se constitua uma equipe as pessoas tem que colocar o que elas pensam [...] todo mundo tem um olhar diferenciado e a somatória disso, é que faz com que a gente construa um trabalho, mais saudável, verdadeiro pro usuário. (E13)

Impossibilidade de participar do trabalho em equipe - permanecendo em sua função

Um dos entrevistados relatou ainda, sua pouca ou nenhuma participação nas várias atividades que caracteriza o trabalho no CAPS, realizando somente atividades do núcleo de competência de sua profissão. Isso ocorre devido à alta demanda de atendimento de pacientes que deveriam ser atendidos em outras unidades da rede de saúde mental e do vínculo empregatício, com carga horária reduzida (20 horas semanais). Porém, esse mesmo profissional, reconhece a função e a importância de sua categoria profissional na equipe, assim como a importância de uma equipe integrada e, mesmo dentro dessas condições, não deixa de expressar seu desejo de ter maior participação na equipe.

Ah, não tenho trabalhado em equipe [...] Até hoje, em 3 meses, participei de metade de uma reunião de equipe [...] me sinto trabalhando num posto de saúde ... (E15)

Frente a esta realidade não podemos deixar de reafirmar a falta de condições de trabalho neste serviço que é também apontada por outros trabalhadores.

\section{Falta de condições de trabalho}

Além da já apresentada, outros trabalhadores também referem às várias questões relativas às condições de trabalhos que acabam por interferir no desenvolvimento de suas atividades. Estas se referem a: falta de conhecimento na área, rotatividade de profissionais e afastamentos, desordem dos prontuários, espaço físico inadequado do serviço, falta de recursos humanos para atender a demanda, falta de recursos materiais e jornada extensa de trabalho. Diante destas limitações os profissionais reivindicam melhores condições de trabalho e identificam necessidades de mudanças tanto na política de saúde quanto em suas ações em direção a uma não acomodação e a maior articulação com a rede.

... é falta de material, a gente ter um espaço maior, a gente tem, assim, uma proposta de mudança de espaço ... (E13)

... a rotatividade de profissionais, então, nós já tivemos 3 ou 4 que eu me lembro na enfermagem, nós temos outros grandes problemas que são os afastamentos, as pessoas adoecem bastante... (E14)

... está faltando um pouco de apoio [...] Autoridades, porque o CAPS está um pouco largado... (E11)

... a equipe do CAPS deveria ser ampliada, pra poder atender a demanda. É uma demanda muito grande, onde você, às vezes, não tem recursos, tanto, humanos, às vezes, material. $\mathrm{O}$ tempo acaba sendo pra um trabalho como esse, 8 horas por dia, é muito pra uma pessoa só trabalhar, que é desgastante, é um trabalho diferenciado, ao mesmo tempo pra demanda é muito pouco... (E5)

... tem uma limitação institucional, a gente não tem condução... mas eu acho isso também, a gente se acomodou um pouco... Ah, não tem carro, mas também... Então, esse ano a gente tem como meta isso, romper isso, ou, de uma forma ou de outra, a gente vai estar cada vez mais nos aprofundando nessa relação com a rede... (E13)

A falta de condições de trabalho nos serviços substitutivos tem sido apontada em alguns estudos ${ }^{(16,18)}$ que abordam o tema demonstrando a necessidade de maiores investimentos na área por meio de implantação e/ou implementação mais intensas de políticas públicas voltadas para a gestão de recursos 
Filizola CLA, Milioni DB, Pavarini SCI. A vivência dos trabalhadores de um CAPS diante da nova organização do trabalho em equipe. Revista Eletrônica de Enfermagem [Internet]. 2008;10(2):491-503. Available from: http://www.fen.ufg. br/revista/v10/n2/v10n2a20.htm

humanos na área da saúde mental, visando melhora nesse quadro. Tais autores acreditam que as mudanças na gestão de recursos humanos no SUS possam ser concretizadas ao se tomar como pressuposto e operacionalizar as propostas da Política de Desprecarização do Trabalho em Saúde ${ }^{16}$. Entretanto, não podemos deixar de assinalar a necessidade deste CAPS, que parece premente, de uma maior articulação com a rede de saúde e, em particular, com a da saúde mental.

\section{RECONHECENDO AS DIFERENÇAS DO TRABALHO NO CAPS EM RELAÇÃO AOS TRABALHOS ANTERI ORES}

Todos os profissionais entrevistados tiveram experiências de trabalho anteriores ao CAPS, o que os levam a refletir sobre no que tais experiências se aproximam ou se distanciam da atual. Ao refletirem sobre a questão, a grande maioria afirma que as experiências anteriores se diferenciam em muito do trabalho realizado no CAPS porém, para alguns, a diferença é quase inexistente.

\section{Sendo diferente}

A maioria que aponta ser a experiência de trabalho no CAPS diferente das anteriores identificando como diferença a natureza das atividades realizadas, a própria organização do trabalho, a nova proposta de trabalho do CAPS e, finalmente, o público alvo atendido.

A natureza das atividades - diferenciando das experiências hospitalares, não sendo um trabalho somente técnico

Alguns dos entrevistados referem ter tido experiências de trabalho hospitalar, o qual, conforme descrevem, diferencia muito do trabalho no CAPS, uma vez que as atividades realizadas no hospital se referiam mais a procedimentos técnicos, sendo que, no CAPS, as atividades concernem mais às relações tanto com paciente como com a família e equipe.

... o que eu fazia era assim mais mecanizado [...] eu não tinha nem tempo pra me comunicar, nem com os pacientes, nem com os nossos amigos de trabalho e, muito menos, com a enfermeira ... (E1)
... você tem que ter mais o cuidado e mexer com o psicológico deles [...] agora não é só aplicar uma injeção. Você tem que lidar com outras coisas também, comportamento, tudo. (E3)

Diante disso, alguns trabalhadores sentem falta de procedimentos técnicos que realizavam em trabalhos anteriores:

... é diferente trabalhar aqui e na Santa Casa. Eu sinto falta [...] falta dos cuidados do paciente, de pegar veia, eu sinto falta de pegar veia, aqui não tem isso. Eu sinto muita falta disso. (E7)

Tais resultados vêm ao encontro da análise do trabalho das auxiliares de enfermagem em um NAPS do município de Santos (SP) uma vez que, também naquele serviço, o trabalho das auxiliares transcendia as funções, especificidades de auxiliares de enfermagem, indo além das ações técnicas, como banho, curativo, medicação, as quais estas trabalhadoras sempre estiveram acostumadas e que nem todas se identificavam com as novas atividades ${ }^{(7)}$.

A organização do trabalho - tendo maior autonomia

Os trabalhadores relatam que no CAPS possuem maior autonomia no trabalho, pois ele é realizado sem pressão por parte da chefia, deixando os trabalhadores livres, para o desenvolvimento de suas atividades.

... a diferença é que as pessoas que trabalham aqui, elas se sentem melhor, porque elas trabalham da maneira que elas querem trabalhar mesmo, elas não têm barreira pra tentar fazer alguma coisa, e você fica livre pra fazer o melhor que você pode fazer, do jeito que você sabe fazer ... (E2)

Autonomia pressupõe liberdade mas, para que o trabalho autônomo seja eficaz pressupõese também capacidade de responsabilizar-se pelos problemas dos outros ${ }^{(6)}$, o segredo, então, para garantir a qualidade em saúde estaria na combinação adequada de autonomia profissional com certo grau de definição de responsabilidades para os trabalhadores, por meio de modos de gerenciar que permita a iniciativa dos trabalhadores sem deixar as instituições totalmente livres sob as diversas 
Filizola CLA, Milioni DB, Pavarini SCI. A vivência dos trabalhadores de um CAPS diante da nova organização do trabalho em equipe. Revista Eletrônica de Enfermagem [Internet]. 2008;10(2):491-503. Available from: http://www. fen.ufg. br/revista/v10/n2/v10n2a20.htm

corporações profissionais $^{(6)}$, o que vem ao encontro da proposta deste serviço tendo em vista a organização do trabalho apresentada.

Possibilitando uma relação mais próxima com os usuários

Diferentemente dos outros trabalhos, há, no CAPS, a possibilidade de maior envolvimento com os usuários, conhece-se cada um, sabe-se da história de cada um, conversa-se com cada um, isto é, há uma relação mais próxima, diferente dos serviços anteriores.

Então, lá (um local de trabalho), a gente não tinha contato nenhum com o paciente. Então, eles chegavam e ia pro pré-atendimento, aí ia pro médico e a gente não ficava sabendo nada, o que eles tinham, se era doente mental, se não era. (E10)

Trabalhando com um objetivo concreto: a reabilitação psicossocial

Trabalhar com o processo de reabilitação social, em outras palavras, buscar a inclusão social da pessoa em sofrimento psíquico é mais uma das diferenças presentes nesse novo trabalho que difere dos anteriores.

... é um trabalho diferente, porque é um trabalho de reintegrá-los a sociedade [...] é um trabalho mesmo de resgate, de integração também entre eles, de socialização. (E17)

\section{Não identificando diferenças}

Embora o trabalho no CAPS tenha sido muito diferente para a maioria dos profissionais, para alguns, é bem próximo de experiências anteriores, uma vez que tiveram outros trabalhos em equipe em saúde mental, diferenciando, às vezes, em pequeno pontos.

Eu não sei se por que desde que eu me formei em todos os lugares de atuação, isso sempre foi algo que existia também [...] eu não vejo muita diferença, porque eu acho que esse olhar da reabilitação psicossocial já existia. (E14)

Entretanto, um dos entrevistados, devido a não possibilidade de participar dos vários momentos do trabalho no CAPS, identifica-o não como o novo modelo de organização do trabalho, mas como apresentando a mesma proposta do antigo modelo assistencial em saúde e afirma:
Ah, é o mesmo tipo de atendimento do Posto de Saúde ... (E15)

VI VENCIANDO DIFI CULDADES NO INÍCIO, ADAPTANDO-SE E APRENDENDO A GOSTAR

Para alguns dos entrevistados o começo do trabalho no CAPS foi considerado difícil, pela dificuldade em realizar atividades que não eram da competência de sua profissão uma vez que não tinham formação e experiência em saúde mental e pelo pré-conceito existente em relação à doença mental, o que levou uma trabalhadora a se adequar ao novo modelo e outra a aprender a gostar. Porém, atualmente, a maioria afirma gostar de realizar todas as atividades, de trabalhar no CAPS e na saúde mental.

\section{Tendo dificuldade em realizar oficina terapêutica no início - tendo que se adaptar e aprender a gostar}

Alguns entrevistados consideraram estranho e difícil ao mesmo tempo o fato de terem que realizar uma atividade específica, a oficina terapêutica. Afirmam que não entendiam o porquê Ihes cabia essa atividade tendo em vista sua formação, e pela falta de experiência e de conhecimento na área, o que implicou na necessidade de se adequar e de aprender a gostar.

... no começo era difícil, fazer oficina. Eu falava: "Eu acho que não é obrigação nossa" [...] a gente foi entendendo [...] quem trabalha aqui tem que se adaptar à portaria... (E1)

... no começo eu não entendia muito bem o que significava, fui aprendendo, fui conversando com a equipe, fui questionando, fui buscando informações teóricas e, hoje, é um local que me agrada bastante em trabalhar ... (E5)

Deve-se considerar que propor uma nova organização de trabalho faz surgir resistência por parte dos trabalhadores e que tal resistência pode ser considerada normal, uma vez que há necessidade de um certo abandono da identidade profissional ${ }^{(6)}$.

\section{Enfrentando o pré-conceito}

Alguns trabalhadores desconheciam 0 serviço associando-o a um local para loucos, um 
Filizola CLA, Milioni DB, Pavarini SCI. A vivência dos trabalhadores de um CAPS diante da nova organização do trabalho em equipe. Revista Eletrônica de Enfermagem [Internet]. 2008;10(2):491-503. Available from: http://www.fen.ufg.br/revista/v10/n2/v10n2a20.htm

manicômio, remetendo à questão da periculosidade da loucura.

... Eu pensei que assim, como seria você entrar dentro de um hospital psiquiátrico, os pacientes agrediam a gente [...] mas aí, eu cheguei aqui, e vi que é completamente diferente... (E10)

\section{Sentindo-se confuso, no início}

Alguns dos entrevistados ainda afirmam, como era de se esperar, tendo em vista a ausência de experiência na área e de capacitação que, no início, não entendiam o que era o CAPS o que os deixou confusos, sem saber como lidar ou agir no serviço.

Me senti confusa, não sabia o que fazer, sabe? Mas aí no dia-a-dia vai acostumando. (E3)

Pesquisas $^{19-20}$ sobre 0 ensino de enfermagem tem apontado a falta formação suficiente para a maioria dos trabalhadores dos serviços alternativos de saúde mental, tendo em vista que o ensino ocorre de maneira fragmentada e teórica, sem refletir para o campo prático, principalmente, para campos alternativos como o CAPS. Segundo estas autoras estes ainda não são vistos pelas escolas como campo de ensino-aprendizagem ficando o ensino ainda centrado no hospital psiquiátrico. Entretanto devemos salientar que há necessidade de uma capacitação permanente para os vários elementos da equipe de saúde mental.

\section{CONSI DERAÇÕES FI NAIS}

Ao analisarmos a vivência dos trabalhadores do CAPS diante da nova organização do trabalho em equipe em saúde mental encontramos, primeiramente, que ele apresenta-se como um processo de construção assentado sobre as relações interpessoais. Neste contexto, os conflitos nas relações de trabalho também se encontram presentes porém, devem ser vistos não como algo negativo mas de forma a impulsionar a criação de estratégias de superação a fim de possibilitar o crescimento dos envolvidos e do trabalho em equipe.

Os trabalhadores entrevistados referem vários pontos positivos relativos à nova organização do trabalho. Dentre eles ressaltamos a possibilidade de criação de vínculo com o usuário o que gera satisfação no trabalho, a presença de maior autonomia e a possibilidade de aprendizado e crescimento demonstrando a importância da nova organização do trabalho em saúde mental tanto para os trabalhadores como para a atenção em saúde mental.

Entretanto, os entrevistados também referem várias dificuldades as quais muitas foram superadas com o dia-a-dia de trabalho, com o contato com os usuários e com o contínuo aprendizado. Porém, dentre as dificuldades a análise do trabalho neste serviço revelou a falta de condições de trabalho como um sério problema a ser enfrentado. Tal questão vem sendo apontada como necessidade de mudanças na gestão de recursos humanos no SUS o que pode ser alcançado mediante a Política de Desprecarização do Trabalho em Saúde. Sendo assim, é premente a implementação urgente das propostas de tal política em busca da concretização das mudanças.

Finalizando, atingido o objetivo da pesquisa, esperamos que ela possa contribuir no processo de construção do trabalho em equipe neste serviço e de outros CAPS contribuindo, assim, na construção dessa nova forma de cuidar em saúde mental.

\section{REFERÊNCI AS}

1. Godoy MGC, Bosi MLM. A Alteridade no Discurso da Reforma Psiquiátrica Brasileira face à Ética Radical de Lévinas. Physis. 2007; 17(2): 289-299.

2. Ministério da Saúde. Saúde Mental no SUS: Os Centros de Atenção Psicossocial. Brasília (Brasil): Ministério da Saúde; 2004.

3. Vilela EM, Mendes AJ M.Interdisciplinaridade e Saúde: estudo bibliográfico. Rev Latino-am Enfermagem. 2003;11(4):525-531.

4. Nicácio MFS. O processo de transformação da saúde mental em Santos: desconstrução de saberes, instituições e cultura [dissertação]. [São Paulo]: Pontifícia Universidade Católica de São Paulo/PUC-SP; 1994. 155 p.

5. Campos GWS. Saúde Pública e Saúde Coletiva:campo e núcleo de saberes e práticas. Ciência e Saúde Coletiva. 2000; 5(2):219-230. 
Filizola CLA, Milioni DB, Pavarini SCI. A vivência dos trabalhadores de um CAPS diante da nova organização do trabalho em equipe. Revista Eletrônica de Enfermagem [Internet]. 2008;10(2):491-503. Available from: http://www.fen.ufg. br/revista/v10/n2/v10n2a20.htm

6. Campos GWS. Subjetividade e administração de pessoal: considerações sobre modos de gerenciar o trabalho em equipes de saúde. In: Merhy EE, Onocko R, organizadores. Agir em saúde um desafio para o público. São Paulo: Hucitec; 1997. p. 229-266.

7. Filizola CLA. O trabalho em um Núcleo de Atenção Psicossocial do município de Santos(SP) - resgatando desejos, reconstruindo projetos de vida em um tempo sem milagres. [tese]. [Ribeirão Preto]: Escola de Enfermagem/USP; 1999. $220 \mathrm{p}$

8. Ferreira SF, Luis MAV. Percebendo as facilidades e dificuldades na implantação de serviços abertos em álcool e drogas. Texto \& Contexto Enfermagem. 2004; 13(2): 209-216.

9. Costa ASSM, Barros S. Saberes e práticas do enfermeiro no trabalho em equipe interdisciplinar de serviços de atenção psicossocial. Resumos dos trabalhos apresentados no 9o Encontro de Pesquisadores em Saúde Mental e Especialistas em Enfermagem Psiquiátrica; 2006 mar 27-30; Ribeirão Preto, Brasil. Ribeirão Preto: EERP; 2006. p. 183.

10. Garcia PRF, Kirschbaum DIR. Reconstruindo Laços, Resignificando a vida: A Enfermagem e seu Trabalho nos Equipamentos de Saúde Mental . Rev. Paul Enf. 2005; 24(9): 10-17.

11. Rocha RM. O enfermeiro na equipe interdisciplinar no Centro de Atenção Psicossocial e as possibilidades de cuidar. Texto \& Contexto Enfermagem. 2005; 14(3):350-357. 12. Mielke FB, Teixeira J unior S, Kantorski LP. O trabalho nos Centros de Atenção Psicossocial resgatando a especificidade da prática do enfermeiro. Resumos dos trabalhos apresentados no 9o Encontro de Pesquisadores em Saúde Mental e Especialistas em Enfermagem Psiquiátrica; 2006 mar 27-30; Ribeirão Preto, Brasil. Ribeirão Preto: EERP; 2006. p. 222.

13. Minayo MCS. O desafio do conhecimento: pesquisa qualitativa em saúde. 10ạ ed. Rio de J aneiro: Hucitec; 2007.

14. Haguette TMF. Metodologias qualitativas na sociologia. Petrópolis: Vozes; 1992.

15. Bardin L. Análise de conteúdo. São Paulo: Edições 70; 1977.
16. Jorge MSB, Guimarães JMX, Nogueira MEF, Moreira TMM, Morais APP. Gestão de recursos humanos nos Centros de Atenção Psicossocial no contexto da política de desprecarização do trabalho no sistema única de saúde. Texto e Contexto Enfermagem. 2007; 16(3): 417-425.

17. Fortuna CM, Mishima ASM, Matsumoto $S$, Pereira MJ B. O trabalho de equipe no Programa de Saúde da Família: Reflexões a partir de conceitos do processo grupal e de grupos operativos. Rev Latino-am Enfermagem. 2005; 13(2): 262-268.

18. Bichaff R. O trabalho no Centro de Atenção Psicossocial: uma relexão crítica das práticas e suas contribuições para a Reforma Psiquiátrica [dissertação]. [São Paulo]: Escola de Enfermagem/USP; 2006. 217 p.

19. Zerbetto SR, Pereira MAO. O trabalho do profissional de nível médio de enfermagem nos novos dispositivos de atenção em saúde mental. Rev Latino-am Enfermagem. 2005; 13(1):112117.

20. Kantorski LP, Silva GB. O ensino de enfermagem psiquiátrica e saúde mental - um olhar a partir dos programas das disciplinas. Rev Latino-am. Enfermagem. 2000; 8(6): 2734.

Artigo recebido em 21.12.07

Aprovado para publicação em 30.06.08 